\title{
Inhalts=Derzeimnis.
}

\author{
II. Ergānzungsband.
}

1. Cetl.

⿰氵ormort

Ingalta.Berzeiđnis . . . VI

I. Sergogtum Arubalt.

13. Berggejes in ber Faffung ber Betenntmadung, betreffend eine neue

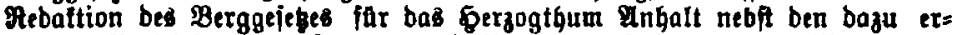

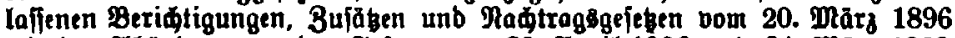



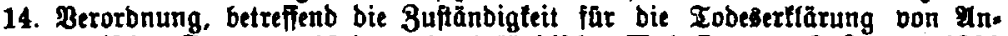

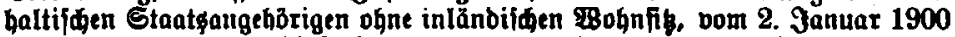

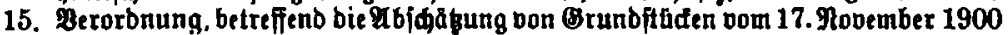

16. Bejes, betreffend bie Benehmigung zu 3umenbungen an juriftifde Perjonen und bie Beauffidtianng von Stiftungen vom 29. April 1904

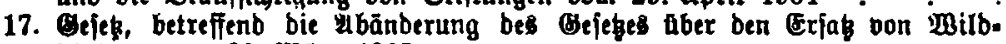
¡́aben, bom 20. Mars 1905 . . . . . .

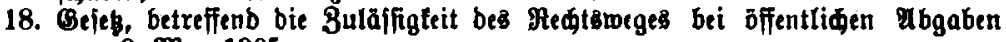
bom 9. Mat 1905

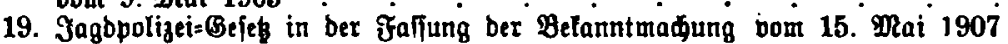

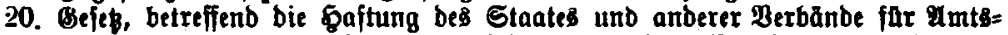
pflibiberlepungen bon Beamten bei Aluôtubung ber offientlidgen Bemalt, bom 2. 2upril 1910 .

\section{Orobbersogtum Baben.}

19. Maffergejes nom 26. Tuni 1899 .

20. Befes. Das Einterlegungswejen betreffenb (Einterlegungborbnung) in ber Faffung ber Befanntmađung vom 30. Juli 1899

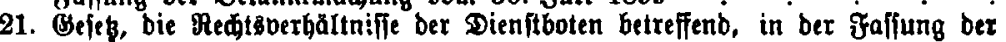
Befanntmađung vom 14. Aluguft 1899

22. Befes, bie Ginfuhrung bet Reidsjuftizgejęe in Grobherzogthum Baben be= treffent, in Der Fafiung ber Betanntmađung bom 30. Stobember 1899 .

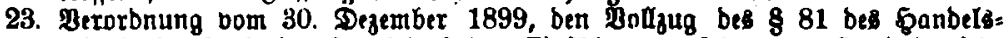

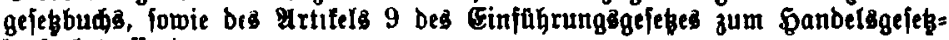
but betreffent

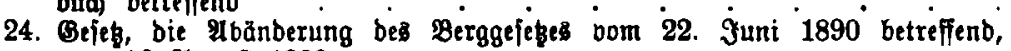
oom 16. Iluguft 1900

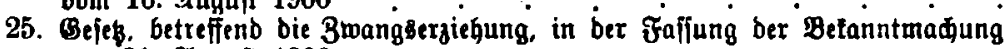
Dom 31. 2ugujt 1900

26. Beroronung. Das Berfahren bei ber 3 manggoerfteigerung und 3 manggoer. waltung betreffend, vom 4. Mai 1901 (8wangsoeriteigerungsberordunng).

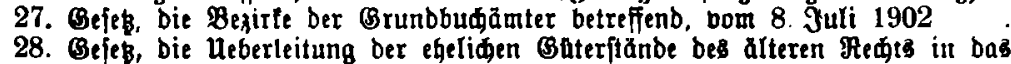

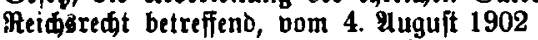

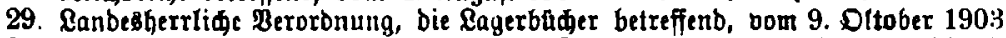

30. Bejes, Das Grunbbudwefen und bie 3wanggoodftredung in Grunbltüte betreffend, bom 13 . Juli 1904 .

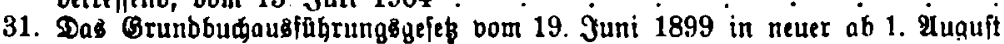
1904 geltender Fuffung 


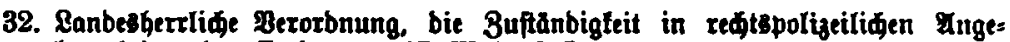
Iegenheiten betreffenb, vom 17 . Dlai 1905

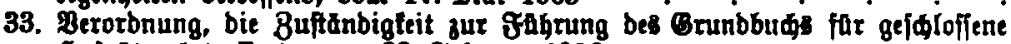
Sofgtiter betreffenb, bom 22. Februar 1906

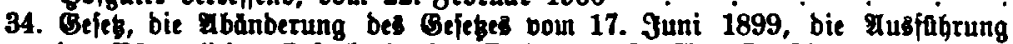
bes gargertiden Bejegbuds betreffenb, vom 25 . surguft 1906 .

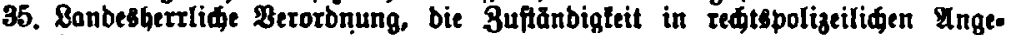
Iegengeiten betreffenb, vom 5. Eeptember 1906 . . . . . . 237

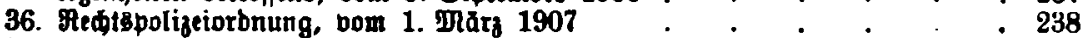

37. Befanntmađung Dom 2. Dejember 1907, bie offentliden Baften ber Brunto= fitude betreffenb

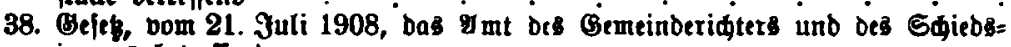
imanus betreffend

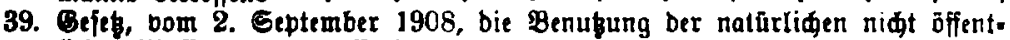

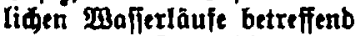

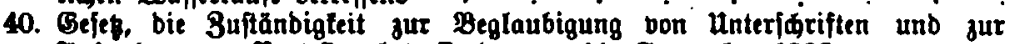
Qlufnabme bon Proteften betreffenb, bom 11. Eeptember 1908 . . .

11. Enteignungsgele vom 26. Juni 1899 in ber Efaffung ber Befanntmađung, bas Enteignungsefés betreffent. vom 24. Dezember 1908

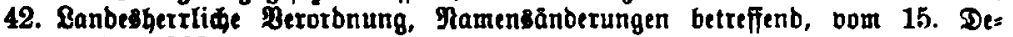
zember 1909

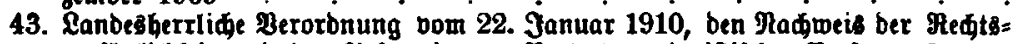
perjönlidfeit unb ber Befiugniß zur :Bertretung juriftiføer Perjonen betr.

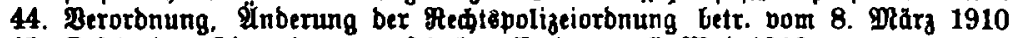

45. Befes, bas ginterlegungsgefes betreffent vom 7. Mtai 1910

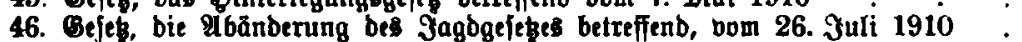

47. RanbeşGerrlidie Beroromung, bie ôffentliden Einterlegungen betreffend, vom 11. Ottober 1910

11I. Azmigreid sayern.

13. Bejeb, bie Fbmartung ber Grunbftade betreffend, vom 30. Yuni 1900

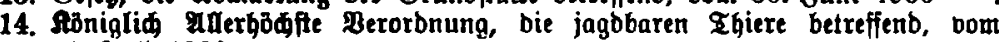
11. Juli 1900 .

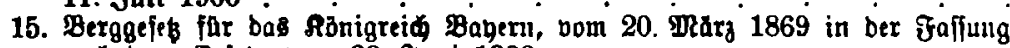
naw bem Befese bom 30. Tuni 1900

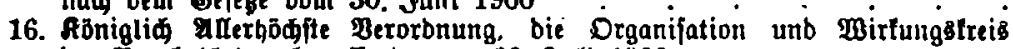
ber Bergbehörben betreffent, vom 30 . Yuli 1900

17. Befę, bas Grjągelo und bas Pänbungšredt unb die Berfolgung vort

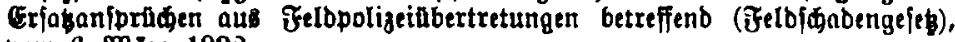
vom 6. Mắz 1902

18. Bejes, bie 3wangsergiehung betreffenb, vom 10. Mat $1902^{\circ}$ :

19. Bejeg, bas Madlabwejen betreffenb, vom 9 . Puguit 1902 .

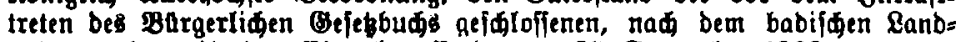
re由le zu beurteilenben Ghen betreffello, nom 28. September 1903

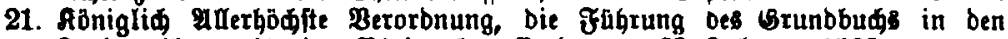
Canbesteilen redts bes Fheins betreffent, bom 25 . Februar 1905

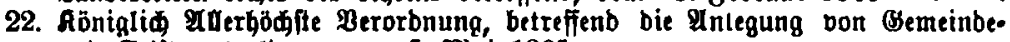
und Etiftungsgeldern, vom 5. Tlai 1905

23. Befes, bie Uleberleitung bon oppotheten betreffend, bom 15. Mai 1906

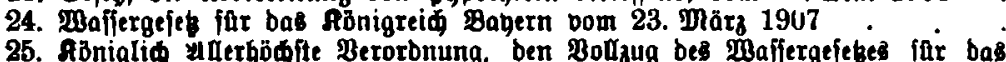

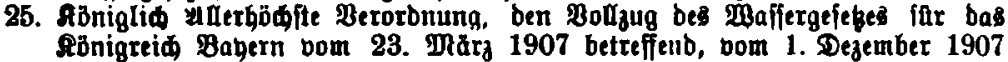

26. Befes, bie Berufovormunbjøalt betreffend, oom 23. Februar 1908 .

27. Bejes, bie Sdecfprotéte betreffenb, vom 16. Juni 1908 . . . . 324

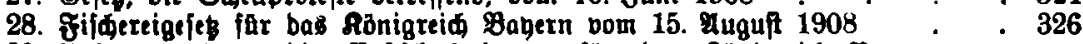

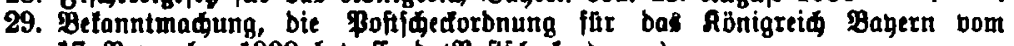
17. November 1908 betreffeno ( Boftígectoronung)

30. Belanntmadumg, bas Pfandoermittelunglgewerbe betr., bom 14. Januar 1909 


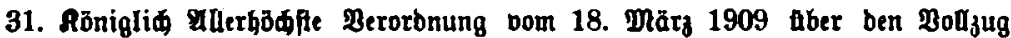
bes ffif

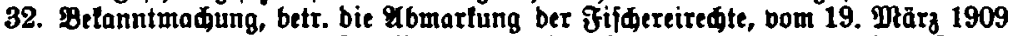

33. Befanntmađung vom 24. Măr 1910, bie Poftidedorbnung far bas Rỏnigs reid Bayern oom 17. Modember 1908 betreffend

34. Befe vom 17. Nobember $1837 / 13$. Auguft 1910, bie Ymangsabtreturg boil Brumb-Cigentum für offentliae 3wedie betreffeno

35. Cefes aber bie Batergertrimmerung vom 13. Qugujt 1910 . $\quad . \quad$. 381

36. Berggejes bom 13. Euguft 1910 . . . . . . . . . . . 385

\section{Sergogtum sraunfowets.}

15. Befę pom 10. Februar 1902 wegen Ulenbernng bes Bejebes, betreffent bas Betwaltungşzwangsber|ałren wegen Beitreibung von Belbbeträgell, vom 9. Ipril $1888 \mathrm{Nx} .16$

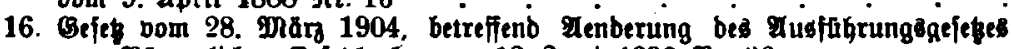
zum Bargerliфen Gejesbude dom 12. Juni 1890 gr. 36 .

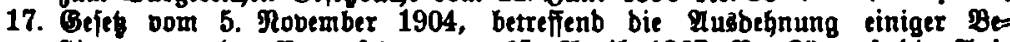
ftimmungen bes Berggejebes oom 15. Sapril 1867 Mr. 23 auf bie शuf= judung und Bewinnung von Erbol.

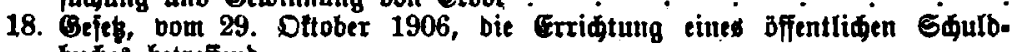
buches betreffenb

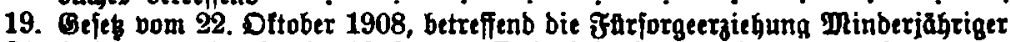

20. Gefes bom 10. Epril 1909, betreffenb Ybänberung bes Bergaejęes nom

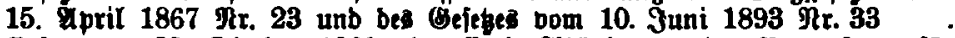

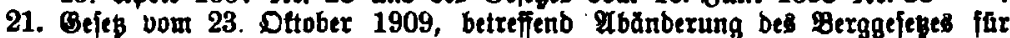

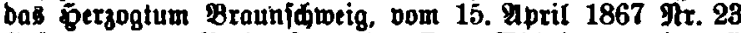

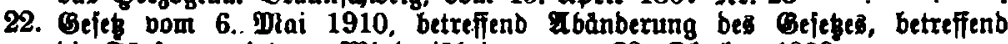
bie đ̛turforgeerziehung Minberjāhriger, bom 22. Dttober 1908

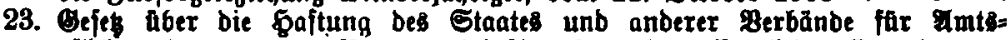
pflidtoerlekungen von Beamten bei \&ubabung ber öfientliden Getoalt, bom 28. Juli 1910 .

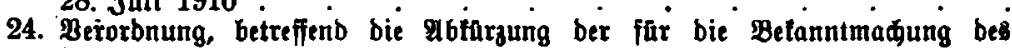

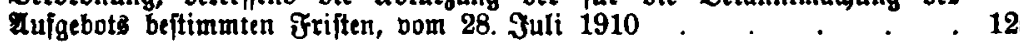

\section{Brete und Sanfeftad Bremen.}

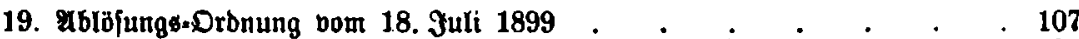

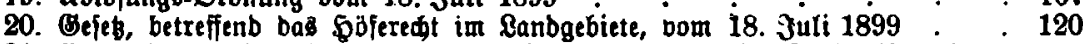

21. Bejeb, bie Bertoppelungen uno Bemeinkeitateilungen im Ranbgebiete betr., bom 18. Juli 1899 .

22. Beies aber bie Enteignung von Grunbeigentum vom 18. Suli 1899

23. Befé, betreffenb Erftattung von Armenunterftąungen, vom 18. 3uli 1899162

24. Sejes, betreffenb bie ftabtbremijide Armenpflege, vom 18. Juli 1899 . 163

25. Bejes, betreffend \&ageríheine und Marrants, vom 18. Juti 1899 . . 165

26. Befe, betrefienb die Befinbeorbnung, vom 18. Suli $1899 \quad$. . 168

27. Befés weget Ergăngung bes Bejeges vom 18 . Juli 1899, betreffenb bie

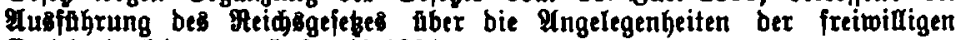
Gerimt barteit, vom 5. 2upril 1901

28. Geję, betreffend bie exblōjung bes Brunbzinjes in Bremergaben, vom 7. Juli 1901

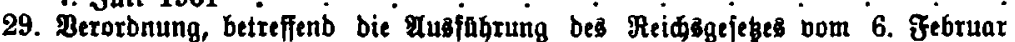
1875 aber bie zeurfunbung bes Perjonenitanbes unb bie Chejhliebung, bom 29. Nobember 1901 .

30. Beję, betrefienb bie 3warigondiftredung im Berwallungswege, vom 29 . De= zember 1901

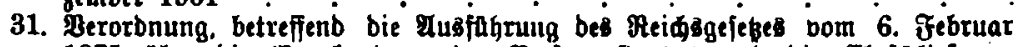

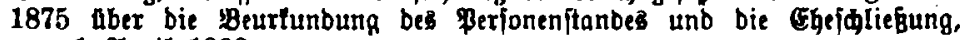
bom 1. Upril 1902 


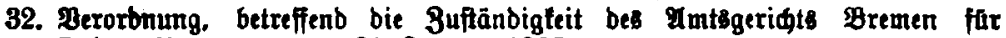
Fobelettlä rungen, bom 31. Januar 1902 . . . . . . .

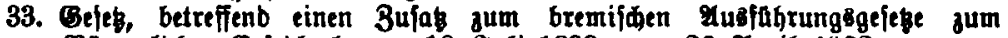

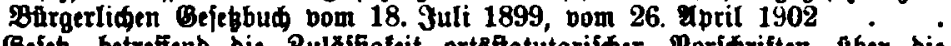

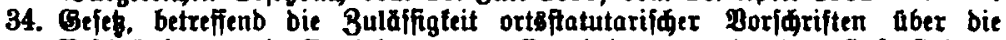
Pejdränfung unb Entzieğung bon Brundeigentum in ben gafenftäbten, bum 25. Juni 1902

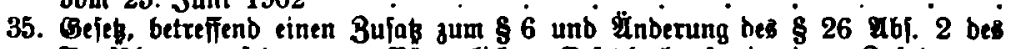

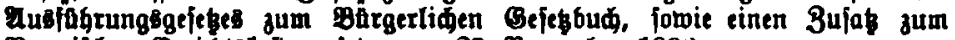
Bremilígen Geridistoftengefes, vom 29. Ptovember 1903

36. Berorbnung, betreffend bie betibigten Börjenmätler, von 3. Januar 1904

37. Berorbnung, betreffend bie beeidigten Baterbefítiger, vom 3. Эanuar 1904

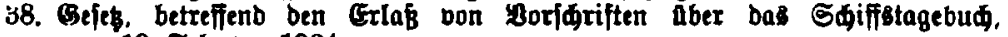
bom 19. İebrutar 1904

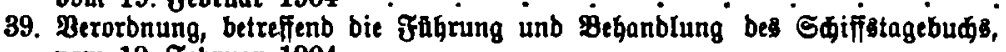
oom 19. Ftbruar 1904

40. Befes, betreffenb bie Ceneraloormunbinaft in ber Stabt Bremen, bour

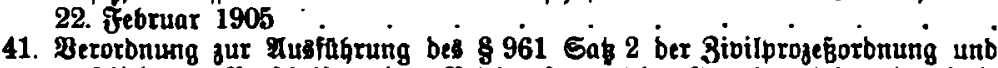

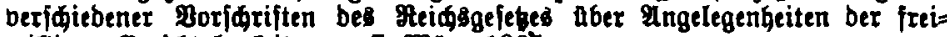
willigen Beridtsbarfeit vom 7. Marz 1905

42. Befeb, betreffend bie Dienjtbarteiten und anbere झedte an folden Brund.

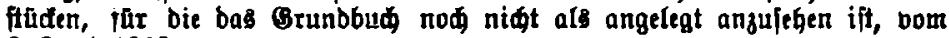
6. Juni 1905

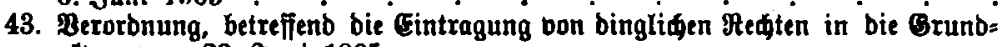
aften, vom 23. Juni 1905

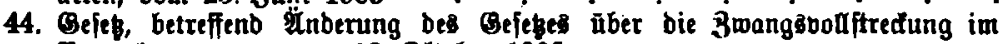
Berwaltungstrege, nom 10. Oltober 1905

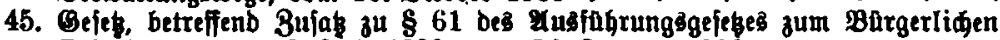
Bejefbude, vom 18. Juli 1899, vom 28. Januar 1906

46. Beleb. betreffenb bie «uffudung und Bewinnung von Bitumen unb Salgen, bom 19. Julit 1906

47. Bejep, betreffend die offentliden Brundlaiten, vom 23. Yuni 1907 .

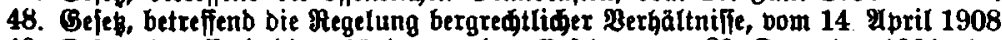

49. Geję, betreffend bie ybänderung bes Befezes nom 29. Dejember 1901, be= treffend bie 3wangebolftredung im Berwaltungemege, bom 15. Juti 1908

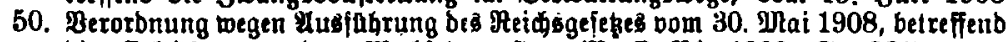

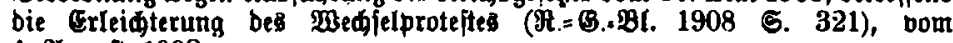
4. $\mathfrak{A}$ ugufit 1908

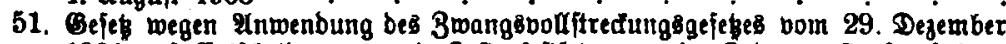
1901 aui Cntideibungen uno Roftenfeftiekungen im Dronungsitrafberiahren an ber Bremer Borje, bom 27. Fuguft 1908.

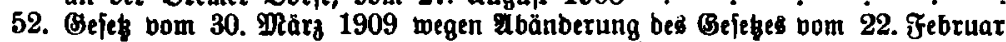
1905, betreffend Die Beneraloormundfigaft in ber Stadt Bremen

53. Berorbmung, betreffenb Dit Beglaubigung bon unterffriften ober \$̇anb=

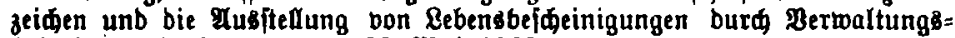
behörben unt Beamte, vom 28. Pat 1909

54. Befeb, betreffend Grbbauredte an folden Brundftuden, far bie bas Brunb=

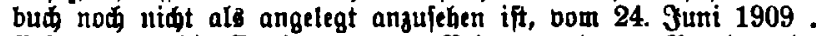

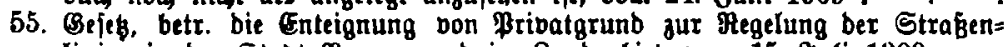
Iinien in Der Stadt 8 remen unb im Ranbgebiet, bom 15. Jufi 1909 .

56. Befeb. Dom 25. Juli 1909, betreffend Abảnberung ber Jagdorbnung bom 27. Dezember 1889

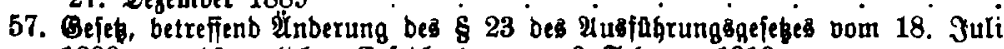
1899 zum bürgerlidgen Geję̧bude, vom 6. Februar 1910

Geite

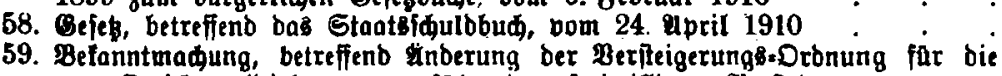

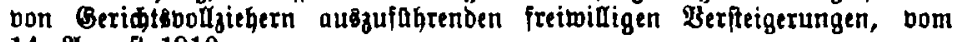
14. Nuguft 1910 
60. Nerordnung, betreffenb Üंnbernug ber शerorbnung aber bie beeibigten Börjenmätler, bom 4. Nobember 1910

Eeite

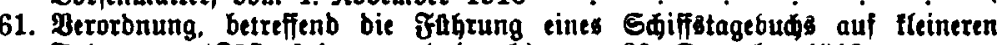
Fabraeugen (Ataftenfabrem und bergl.), vom 20. Dezember 1910

\section{Meihsland Glapasothringen.}

13. Berorbnung, betr. bie bffentlide Bejtellung und bie allgemeine Becibigung bon Gadberflănbigen, bom 6. Tanuar 1902

14. Berorbmung, betreffend Den Baterftand ber bor bem $\dot{S}_{\text {intraftreten bes }}$

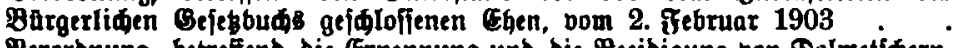

15. Berorbnung, betreffenb bie Ernennung und bie Beeibigung bon Dolmetidgern, oom 13. Juni 1903 .

16. Cefes. betreffend die Mefitgberhaltniffe ber Dienjtboten (Gefindeorbinung). vom 26. JuIi 1903 .

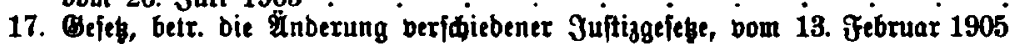

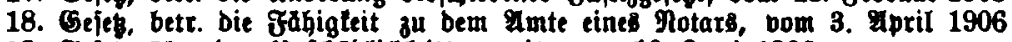

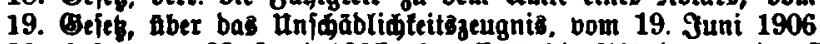

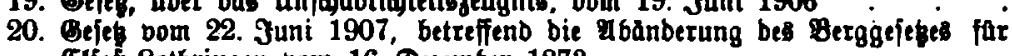
Cljaks\&othringen bout 16. Dejember 1873 . .

21. Bejep, betreffend bie פbtretung bon Brunbeigentum ju Meliorationszioeden, bom 30. 3uli 1907

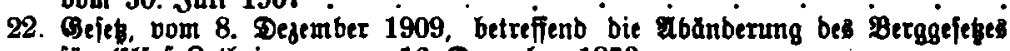
für Elja $\mathrm{B}=8$ othringen oom 16 . Dejember 1873

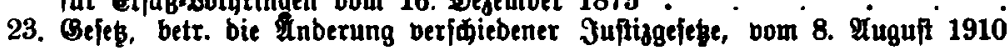

\section{Frete uno sanfefiabt samburs.}

12. Belauntmadung, betreffenb ba Brunbbudmefen vum 11. Dezember 1899, ergångt burd Đefanntmaüung vom 14. Tamuar 1901

13. Dienftbotenorbnumg vom 7. Dejember 1898

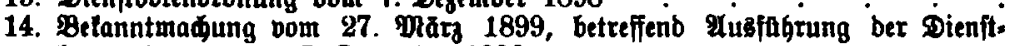
botenorbnung pom 7. Degember 1898

15. Geję bom 27. September 1899, betreffent 2 bănberung bes Expropriations: gefétes vom 5. Plai 1886

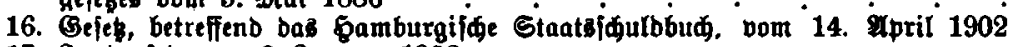

17. Jagbgefes bom 2. Januar 1903

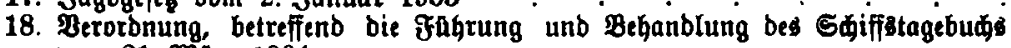
bom 21. Măr 1904

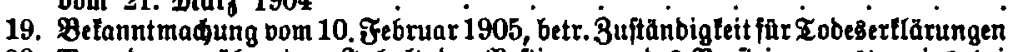

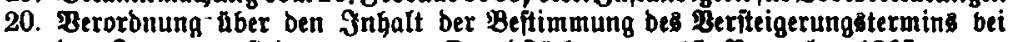
ber 3twang8verfteigerung von Brunbftuten vom 15. Nobember 1905

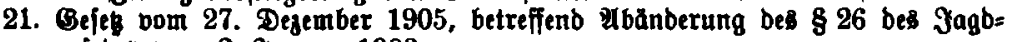
gefebes bom 2. 3anuar 1903

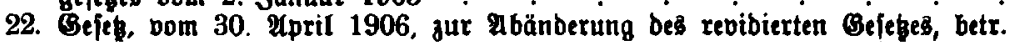

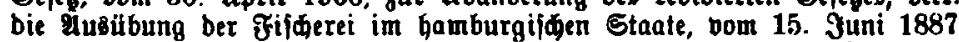

23. Gejes bom 25. Juni 1906, uber Die Bewinnung von Stein= unb falifaljen

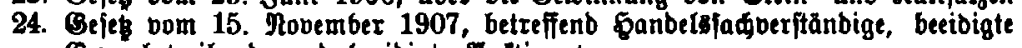
Bewerbetreibente und beeibigte Puftionatoren

25. Bejeł vom 18. Jamuar 1909 zur Mbänberung bes Befétes, betreffenio bas Notariat, bom 29. Dezember 1899

26. Oeję aber bie öffentlide Farjorge făr minberjährige in ber Faffung nom 9. Februar 1910

27. Beies aber bie 3 wangserziebung $\dot{\mathfrak{T}}$ inberjałbriger in ber faffung vom 9. Jebruar 1910

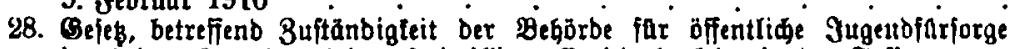

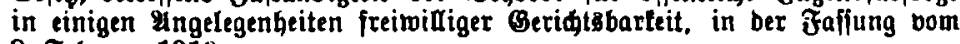
9. Jebruar 1910

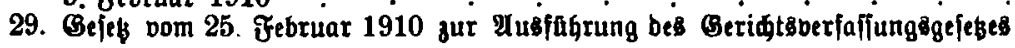




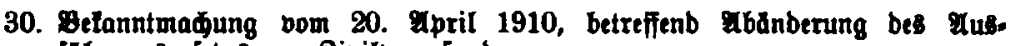

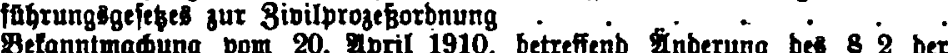
Einterlegungsoronung oom 14. Juli 1899 . .

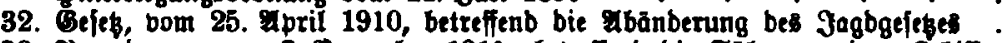

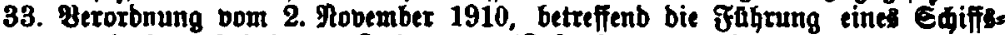
tagebudg auf tleineren Fahrzeugen (Raftenfabrern u. bergl.)

Ecite

VII. Orobhergogtum Eefien.

21. शిerorbnung, baß Getwerbe ber Pfanbleiber unb Irōbler betreffenb, boun 2. Fuguft 1899

22. Befeb, bie BefinbesDibnung betrefient, vom 28. 29pril 1877, in ber f̛afjung bom 3. Euguft 1899 .

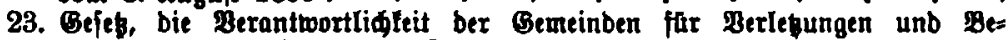
jadabigungen in Folge bon 3ujammenrottungen betr., bom 3. Mlärz 1859 in ber frafiung vom 30 . September 1899 .

24. Oejeb, bie Familien=જ́ibeifommiffe betreffent, vom 13. Geptember 1858 in ber Jैafiulg vom 30. Eeptember 1899

25. Befeb, bie Enteignung von Grundeigenthum betreffent, oom $26 .{ }^{\circ}$ Эuli $1884^{\circ}$ in Der Falfung vom 30. September 1899 .

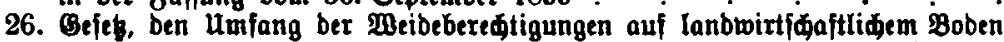

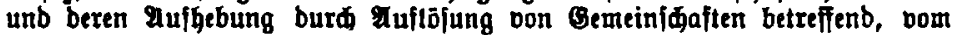
7. Prai 1849 in ber fafinung bom 30 . Eeptember 1899 .

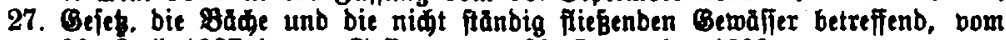
30. Jufi 1887 in Der f Faffung bom 30. September 1899 .

28. Berggefę fûr bas Broßhergogtum छefien bom 28 . Januar 1876 in ber Fafjung vom 30. September 1899

29. Gefeb, bie 3wangserjiehung Ptinberjühriger betr., vom 11. Ganuar 1887 in Der Ffaffung vom 30. September 1899

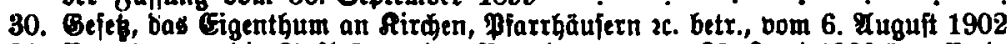

31. Betoronung, bie Gufhebung ber :Betoronung bom 20. Juni 1900 betreffenb, vom 30. Juli 1902 .

32. Berorbnutg, betreffenb bie Ergănuung bex Berorbnung, bie geriditliden Einterlegungen betreffeno, vom 19. शuguft 1899, bom 7. Sanuar 1903

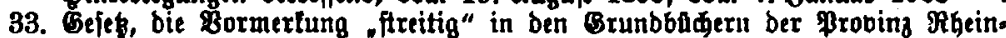
heffen betreffenb, bom 30. Mara 1903

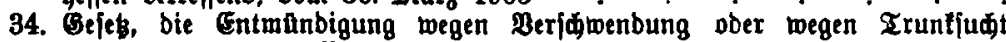
betreffend, vom 31. Mara 1903

35. Bejes, bie Ieilung belafteter Brunbjtưfe betreffeno, bom 27. Jưli 1904

36. Bejeh, bie Berwahrung bon Derfingungen von Tobeswegen betreffend, bom 30. Dezember 1904

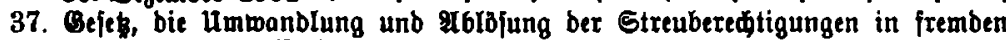
Baloungen betreffent, bom 4. Januar 1905.358

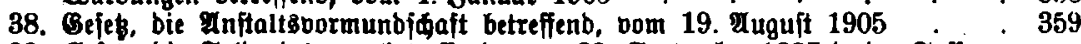

39. Bejeß, bie Felbreinigung betrefferb, bom 28 . September 1887 in ber Faffung vom 7. Juli 1906

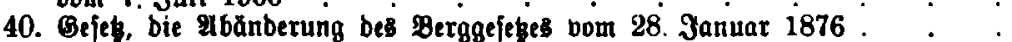

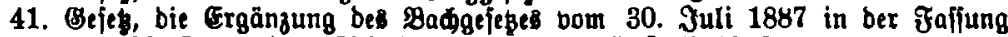
bom 30. September 1899 betreffent, vom 15. Juli 1908 .

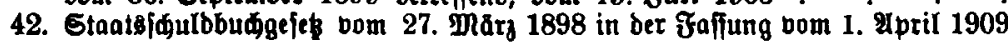

\section{Fufftentum sippe.}

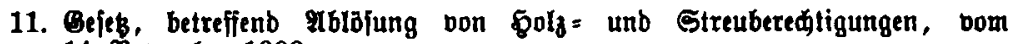
14. Nobember 1900

12. Raubesherrlide Berorbnung bom 15. Plai 1902 wegen Crlduterung ber

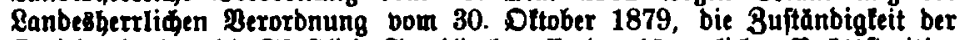

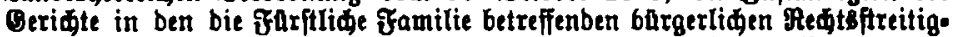
teiten unb Angelegenheiten ber freiwilligen BeriळtBbarteit betreffent 


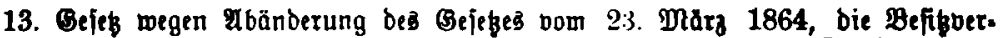
änberungen tei Brunbitüưer und beren Cintragung in bas Ratafter betr., nom 10. Dezember 1902

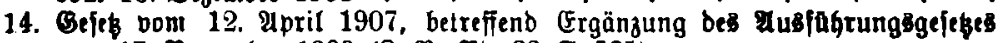

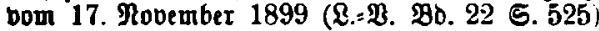

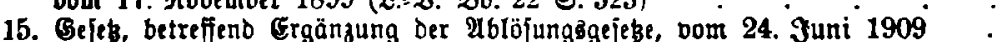

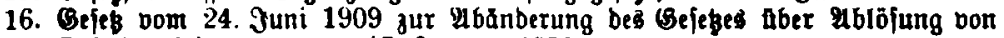
Gubeberectigungen vom 17. Jaluuar 1850

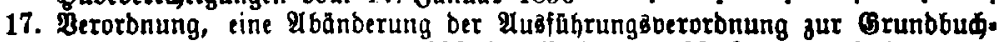
orbnuitg vom 18. Dezember 1899 betreffent, nom 28. Januar 1910 .

\section{8retc unb saufeftabt sabce.}

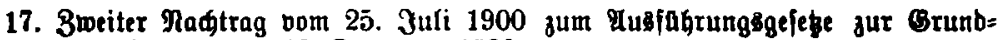
buњorbnung bont 18. Dezember 1899

18. Berorbnung vom 18. Thai 1901 , betrefieno bie Rusftugrung bes \& 5 bes

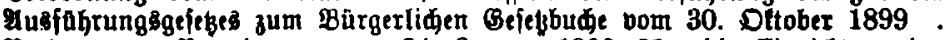

19. Naळtrag zur Berorbnung voln 24. Januar 1900 ther bie Eintidtung ber Grunbbther bour 5. Thai 1902

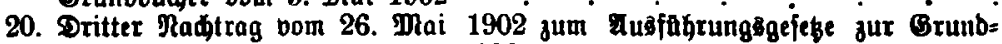
buforbnung bom 18. Sezember 1899

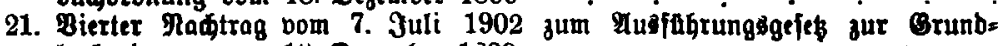
budforbnung bom 18. Sezember 1899

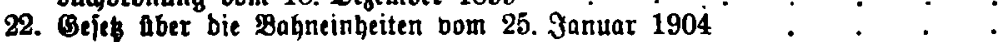

23. Berorbnung, betreffent bas Bagngrunbbud, bom 25. Yanuar 1904 . bom 13. F Februar 1904

25. Pađtrag bom 18. Oltober 1905 zur Notariatoorbmung bom 23.

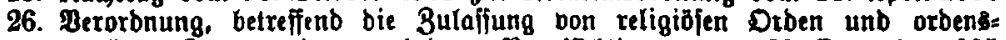
ăbnliden Rongregationen unb beren Beauffidtigung, bom 20. Dezember 1905

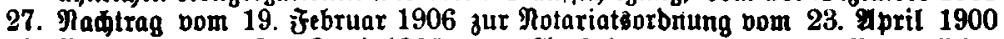

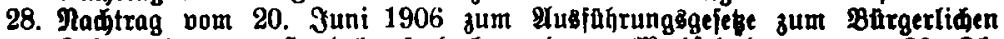

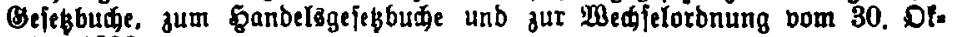
tober 1899

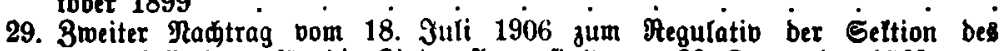

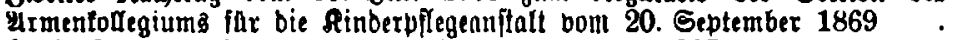

30. Jagbgefes bom 28. Februar 1900 im Peubrita bon $1907:$ : .

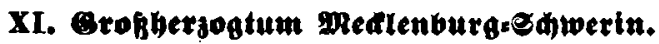

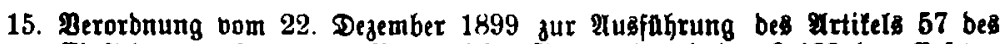

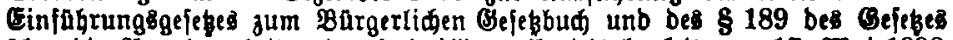
ther bie थngelegenketten ber freiwilligen Beridtsbarteit vom 17. \$Dai 1898

16. Derorbnung vom 24. Märg 1904, betreffenb bie Fuhrung unb Behanblung be Satifistagebuds.

17. Verorbnung oom 24. Iuguijt 1904 zur 2lisfahrung Der Cinfahrungsgejege

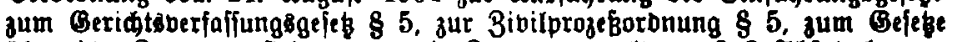

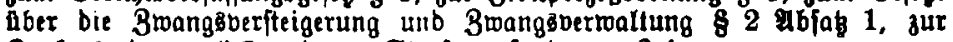
Rontursorbnung $\$ 7$ und zur Strafproze Borbnung 84

18. Derorbnung vom 17. Februar 1905, betreffend $\mathfrak{Y}$ erănberungen im Beftande ber in ben ritteridaftliden \$ufenfatafter eingetragenen Ranbghter unb

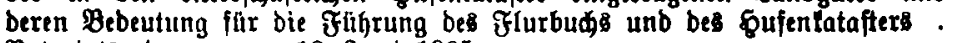

19. Notariatsorbnung vom 10 . Tuti 1905

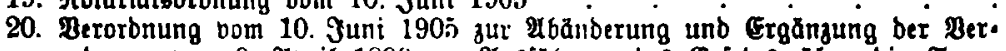

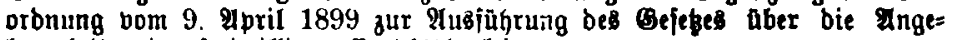
Iegenheiten ber freimintigen (serimtabarteit

21. Derorbnung vom 8. Februar 1906 zlir $\Re$ bänberung ber Derorbnung vom 9. Epril 1899, betreffend bas Berfahre!l bei ber 3mangboolftredung im Berwaltungsoege 


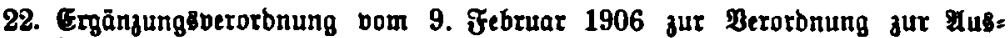
fahrung bes BargerIiden Befesbud vom 9. 2pril 1899 . . . .

23. Betpronung bom 28. Dlăr 1908 zur Crlătetung ber Beroronung vom 9. Pupril 1899 zur Pusfahrung bes margerliden Bejegbuds . . .

24. Petorbmung bom 18. Dlai 1908 zur Rubfăhrung bes Ederf̈gelęes . .

25. Perorbıung bom 6. Ipril 1909 zur Mbänberung ber Berorbnung vom

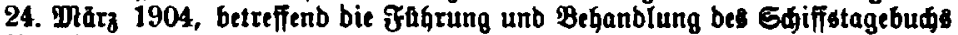

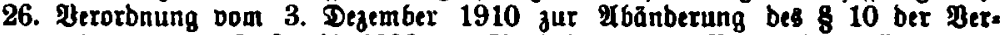

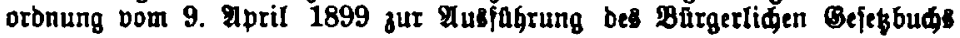

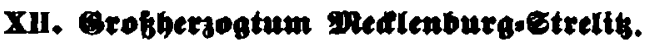

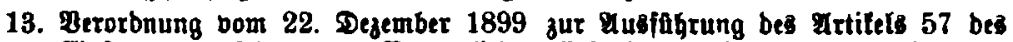

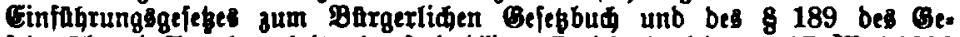

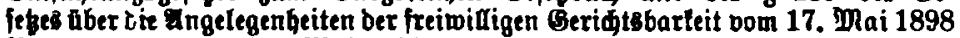

14. Berorbnung vom 16. Drai 1902 zur Ergănzung ber Perorbnung vom 26. Yanuar 1880, betreffenb bas Mtotariat

15. Berorbnung bom 15. September 1904 zur श्äfabrung ber Cinfubrungs:

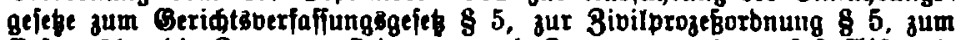

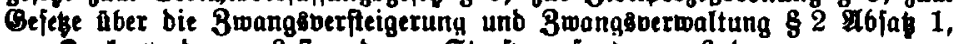
gur Aonfursorbnung \$ 7 und gur Strafprojéborbnung \& 4

16. $\mathfrak{B e r o r b n u n g , ~ b e t r e f f e n d ~} \mathfrak{B}$ erånderungen in Beptanbe ber in ben ritteridaft= Iicen \$ujenfatafter eingetragenen Ranbguter unb beren Bebeutung für bie

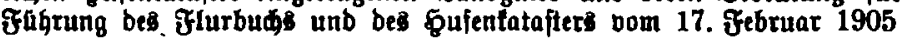

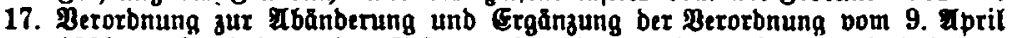

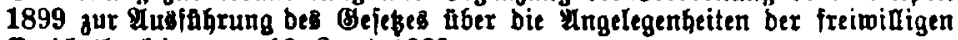
Beridgtbarteit, bom 10. Juni 1905.......

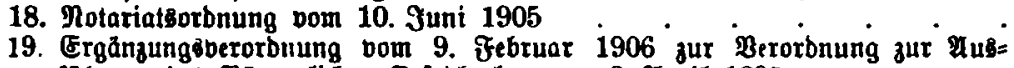

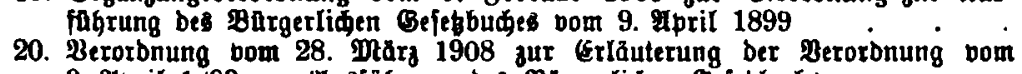
9. அpril 1899 zur

XIII. Brofberzogtum Orbenburs.

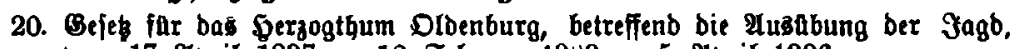
bom 17. April 1897 - 12. Ffebruar 19 j0 - 5. April 1906

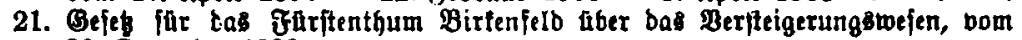
30. Dejember 1899

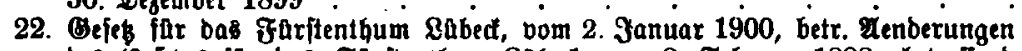
bes Befepes fár bas forâtenthum sabed vom 8 . Februar 1888, betreffent bie Yustabung Dex $3 a g \delta$.

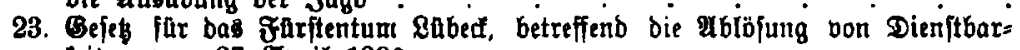
teiten, vom 27. Epril 1900

24. Berorbnung fâr bas Eerzogthum Dibenburg betreffeno Beglaubigungen von

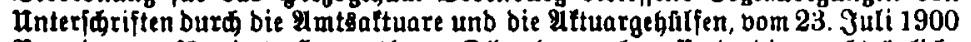

25. Berorbnung fär bas \$erjogthum Olbenburg, betreffent bie nađtrăgliđe Inlegung von Brunbbudblăttern far budungspflidtige Brunbitude, vom 20. थuguft 1901

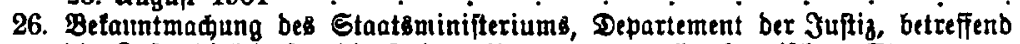

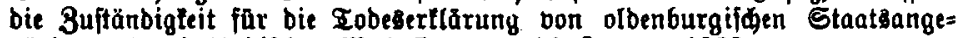

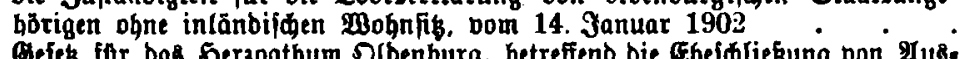

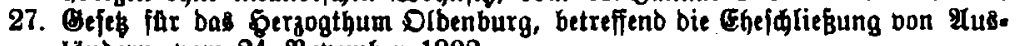

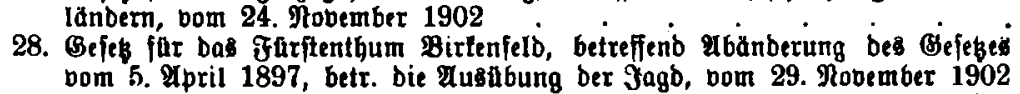

29. Bejes far bas (Srobgergogthum Olbenburg, betreffenb bie Tublegung bes Qrititels 77 bes revibierten Etaatşgrundgefeges, nom 16: Dezember 1902.

30. Befes fitr bas Gerzogtum Dlbenburg, betreffend bie Beftellung von PFand-

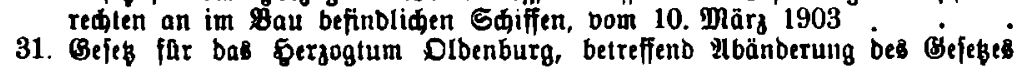




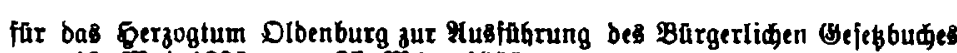
bom 15. Plai 1899, vom 27. Mårz 1903

32. Berorbnung far Das \$ergogtum Olbenburg, betreffend feftiegung Der Be: Ieihungsgrenze fár Mänbelgeld, bom 27. Dhăr 1903

33. Perorbnung fur bas Ftarftentum \&abed, betreffenb bie Befugnis ber bei bem Stabtmagiftrat Eutin angeffellten 9 ftuare zur Beglaubigung von थbitififten

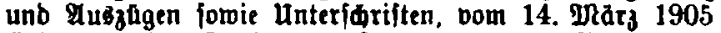

34. Gejeb, far bas Farftentum \&abed, betrefienb Beitellung boit gypothelen für Q

35. Bejes fur bas \$erzogthum Olbenburg, befrefiend Beftellung von छgpotheten fár éblöjungätapitalien oom 19. Dezember 1905

36. Bejes fur bas Grobberzogtum Oibenburg, betreffend ëhberung von familien= namen und Dornamen, bom 22. Dezember 1906

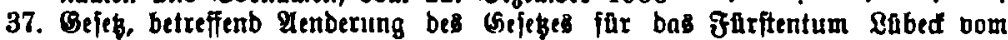
8. Februar 1888, betr. bie 2rustubung ber 30gb, vom 14. Ffebruar 1907

38. Geję bom 25. Plär 1907 tat bas Serzogtum Olbenbutrg, betreffend

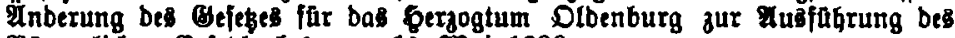
Bargerlinen Befesbuwes bom 15 . Thai 1899

39. Berggefes fur bas Eerzogtum Dibenburg und finc bas Fürftentum Babed, vom 3. थpril 1908

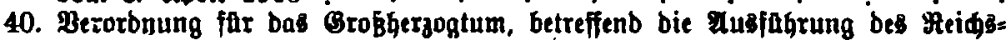

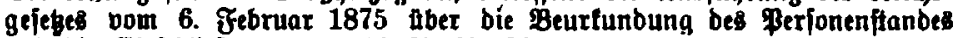
unb bie Chelfiließung, bom 11. Upril 1908

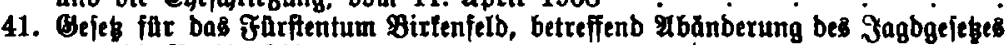
bom 11. 2lpril 1908 .

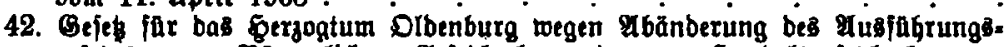
gefeges zum Bargerliden Befesbudie unb jum sandelogejębude bom 15. Mai 1899 , bom 18. Mai 1908

43. Befes far bas Brobhergogtum Orbenburg, betreffend bie \$aftung bes

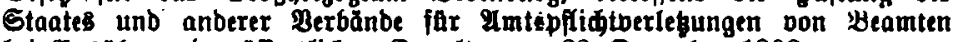

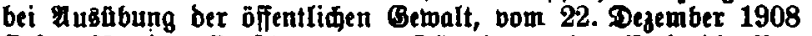

44. Befes, far bas Groß̉bergogtum Dlbenburg. betreffend bie Berufgoormumb. f(daft, bom 29. Dezeulber 1910

Eeite

140

141

143

144

146

149

189

189

\section{Abnigretd greufen.}

\section{2. artl.}

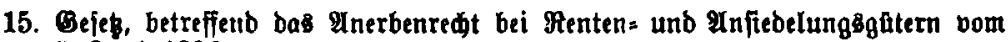
8. Juni 1896

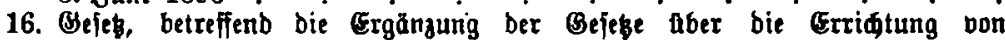
Plarffteinen vom 7. Otlober 1865 uno vom 7. श्pril 1869, bom 24. Mai 1901

17. 3agboronung für bie \$ohenzollernjめen Ranbe vom 10. Ptăr 1902

18. Bejeb uber bie Bahneinheiten vom 19. Auguft 1895, abgeănbert burd Befés bom 11. Juni 1902 in ber Faffung ber Betanntmafung vom 8 . Juli 1902

19. Befe bom 7. Juli 1902 , betreffenb bie Mbanberung eiluzelner Beftimmungen

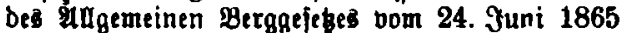

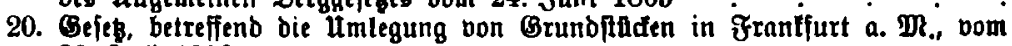
28. Jưli 1902 .

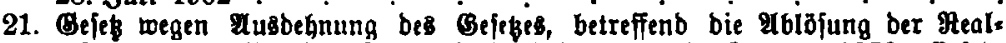

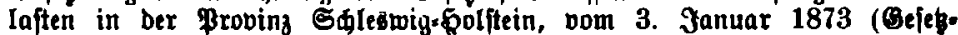
Gamml. (5. 3) auf ben freis Eerzogtum Rauenburg, bom 29. Mai 1903

22. Bejes, betreffenb Bebauung und benubung ebemaliger mallgrundftate in Frantfurt a. $\mathfrak{P}$., bom 4. Juni 1903

23. Berorbnung wegen Poänberung ber Beroronung vom 15. Nobember 1899, betreffend Das शerwaltungszzwangberfahten wegen Beitreibung bon Beld. betrăgen, vom 18. März 1904 .

24. Bejes, betr. bie Wedjelprotejtitunden, pom 1 Juni 1904 . . . 250

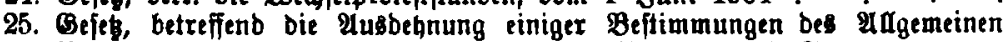
Berggejebes bom 24. Juni 1865 auf bie Huffudung und Betwinnung bon Groöl, vom 6. Juนni 1904 
26. Befeb, betreffend bie Fusbegnung einiger Beftimmungen bes đagemeinen


Gtein: unb Ralifala unb bon Golquellen in ber Probing \$annober, bom 26. Juni 1904

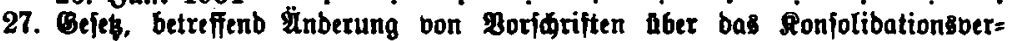

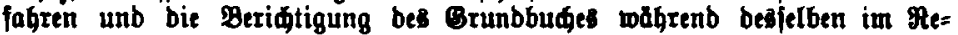
gierungsbegirle Miesbaben, bom 4. Iuguft 1904

28. Befes aber bie Beftellung bon Salzabbaugeredtigteiten in ber Provinz Eannober, bom 4. Auguft 1904

29. Befeł, betreffenb die Bründung neuer Anfiebelungen in ben Probinzen Ditpreuben, \$eftpreuben, Branbenburg, Bommern, Pojen, Sdlefien, Sadjen unb 2 eftfalen, bom 10 . Ouguft 1904

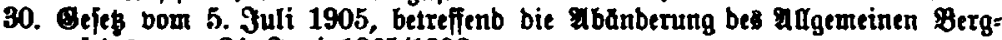
geleges bom 24. Juni 1865/1892

31. Gefeb vom 14. Iuli 1905 , betr. bie श्abänberung einzelner Beftimmungen bes yagemeinen Berggefefes bom 24. Juni 1865/1892

Selte

2. Berorbnung, betreffend bie Bufiandigteit für bie Entgegennahme ber

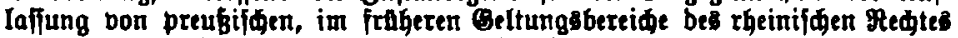
belegenen Brunbftúden dom 27. Dezember 1905

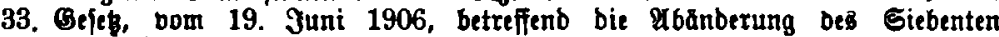

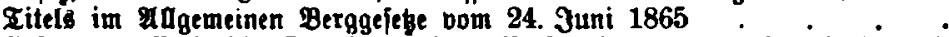

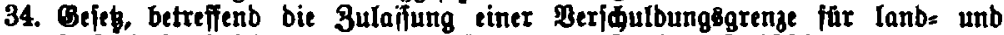

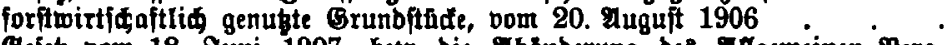

35. Bejeł Dom 18. Juni 1907, betr. bie æabảnberung be घafgemeinen Berge gejeges oom 24. Juni 1865

36. Jagborbnung, vom 15. Juli 1907 .

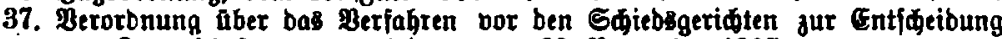
von Rnappidaft angelegenhetten, bom 29. November 1907

38. Derorbmung ther bas Berfahren nor bem Oberjhiedsgeridt in Anappidafts. angelegengeiten, vom 30. शovember 1907

39. Derorbnung aker bie Ginfubrung bes (jejepes. betreffend bie 3ulafing einer Berjhulbungsgrenze far Ianb: unb forftmirtidaftlid genubste Brunb=

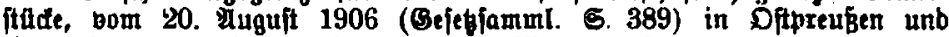
einem Zeile von Mefipreußsen, vom 23. DRär 1908

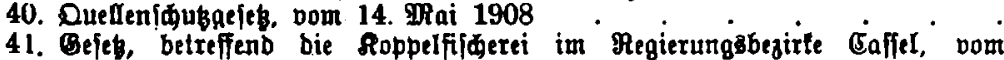
19. Mai 1908

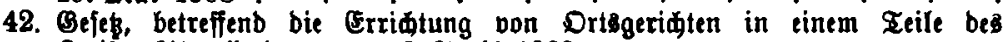
Areifes Altenfirden, vom 13. April 1909

43. Berorbnung, betrefiend bie Drtßgeriatte in einem Teile bes Areijes firden, bom 24. Dlai 1909

44. Berorbnung Liber bie Einjahrung bes Bejebes, betreffend bie Bulafiung

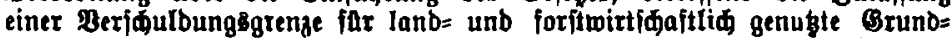
fithte, bom 20. 2Auguf 1906 (Belebjamml. פBeftpreuken und in ber Provinz Pofen, vom 16. Juni 1909

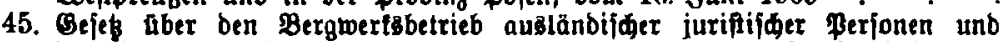

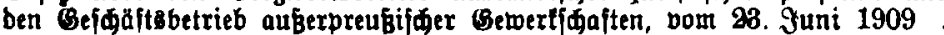

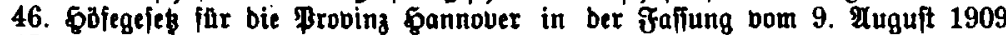

47. Bejeł, betr. bie $\mathfrak{a b a n b e r u n g}$ bes angemeinen Berggejeges vom 24 . Juni $\frac{1865}{1892}$ unb 14. Juli 1905, vom 28. Juli 1909

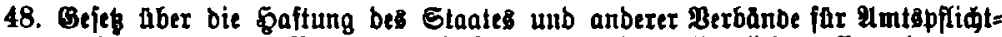
verlegungen von Beamten bei Rusabung ber Bffentliden Bewalt, bom 1. भuguit 1909

49. Beroronung gur Ougfahrung bes Bejezes uber Den Bergwertsbetrieb aug-

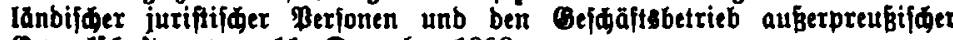
Betwerlidaften, bom 11. Dezember 1909

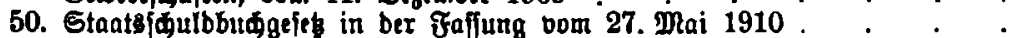

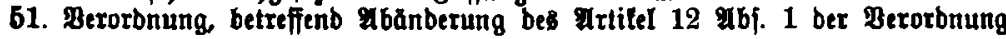




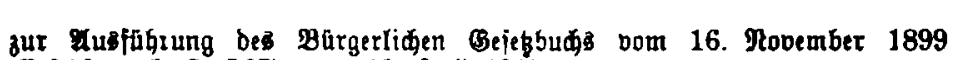
(Gejebjauml. 5. 562), vom 12. Juti 1910. . . . . . 407

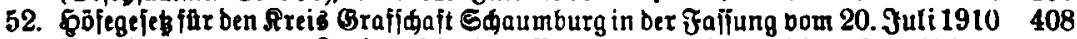

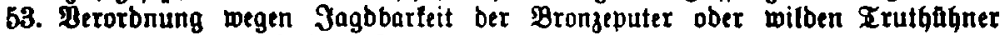
(Frutwilb), bom 9. Puguit 1910

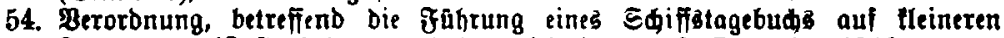
Fahrzeugen (Aaftenfahrern und Dergleiden), vom 9. Dezember 1910.

XV. Burftentum gcub Aelterer Rinic.

11. Ranbesherrliđe Berorbnumg vom 30. Tezember 1899, bie Augfahrung bes

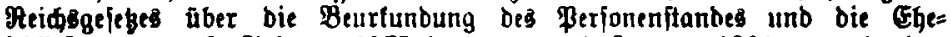
¡d dießsung bom 6. Februar 1875 in ber bom 1. Januar 1900 an geltenbent Faffutis betreffenb

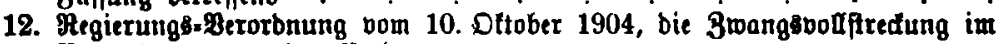
Berwaltungswege betreffend

13. Gefes bom 9. घpril 1907 zur $\mathfrak{A b a ̈ n b e r u n g ~ u n b ~ G r g a ̆ n g u n g ~ e i n i g e r ~} \mathfrak{B}_{e}$ : ftummungen aber bas $\mathbf{3}$ tangsenteignungsoerfahren .

14. Fegierung8= Beroronung bom 23. Fobember 1907 , bie Beitreibung ber Soften Der Plotare im Serwaltungs̆mege betreffent

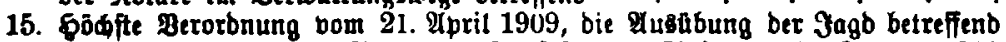

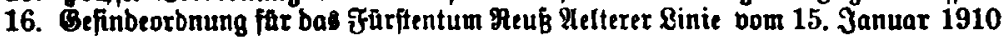

420

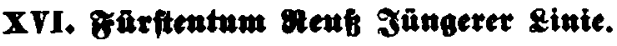

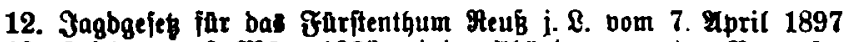

13. Gejeb vom 9. Măr 1903, einige abänberungen Des Berggeję̧es betreffend

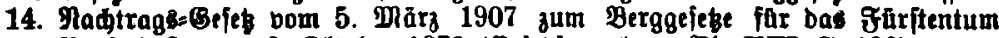

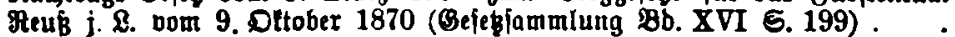

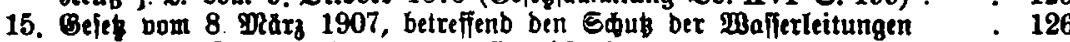

16. Befes taber Bulammenlegung von Grunbftaten vom 6 . Juli 1909 . 128

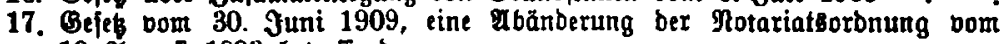
10. 2uguft 1899 betreffend

XVII. Rzuigretio Sadien.

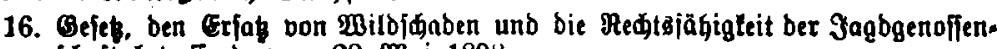
ífaft betreffend, bom 28. Daai 1898

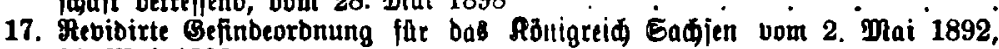
31. Dtai 1898

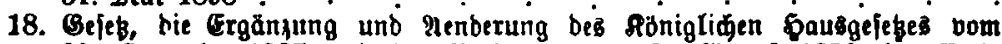
30. Dezember 1837 und beş Radtrags nom 20 . श्aguft 1879 betreffenb. vom 6. Juti 1900

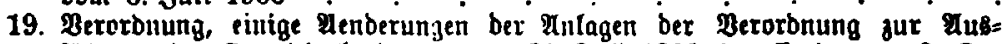
fabrung ber Brunbbudorbnung bom 26. Jult 1899 betreffend, oom 2. De= zember 1901

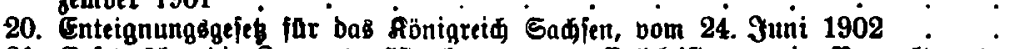

21. Bejes tber bie 3wangsoouftrefung wegen Belbleiftungen in Berwaltungs: jaden, bom 18. 3uli 1902

22. Befes, bie Aufbebung Der mit Ipothefengeredigteiten berbunbenen \$erbietungsisedte betreffend, vom 24. Juni 1902

23. Berorbnung bom 27. Plär 1905 , bie भ̈nberumg bes 847 Der Berorbnung zur Æusführung ber Brunbbudorbnung vom 26 . Yuli 1899 betreffend

24. Derorbnung vom 12. Plai 1905, eine Mbånberung ber Perorbnung jur

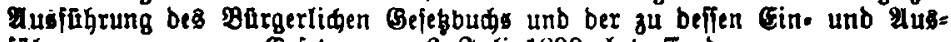
fabrung ergangenen Gefege, bom 6 . Juli 1899 , betreffend

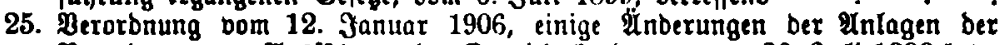

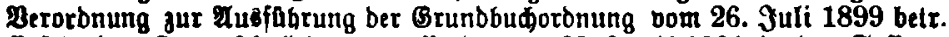

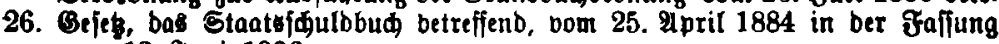
bom 12. Juni 1906 .

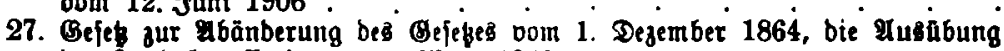
ber Jagb betreffenb, bom 9. März 1908 


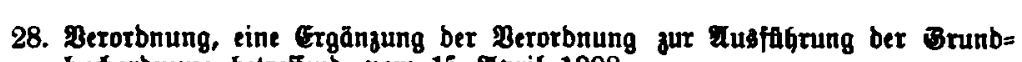
budorbnung betreffenb, vom 15. Ipril 1908

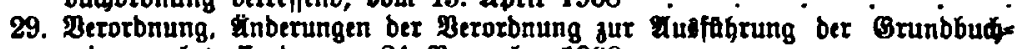
orbnuntg betreffent, bou 24. November 1908

Geite

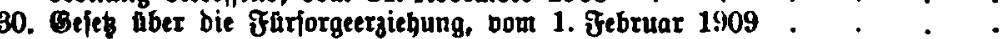

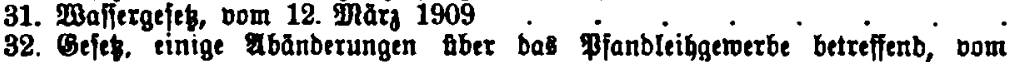
27. Phai 1910

33. Bejes, bie neue einheitlide falfung ber gefanten Berggejebgebung enthaltend, vom 31. Juguît 1910 .

\section{Serzogtum Gadienafitenburg.}

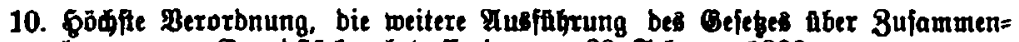
legung bon Grunbftuden betreffent, voun 20. Februar 1900

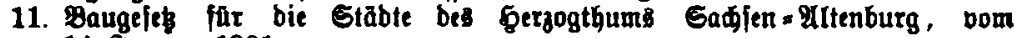
14. Januar 1901 .

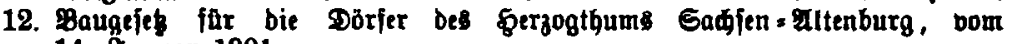

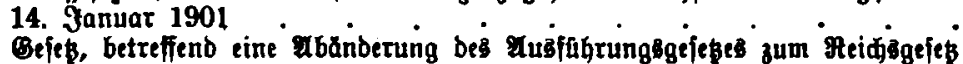

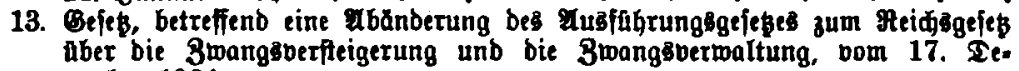

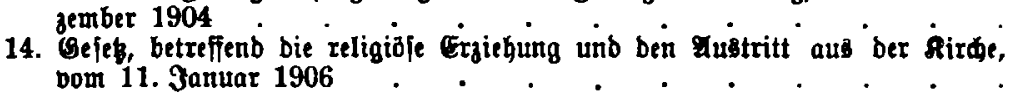

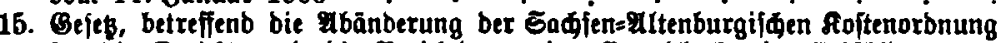

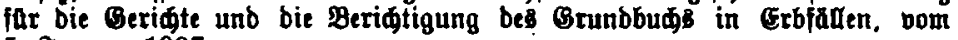
5. 3anuar 1907

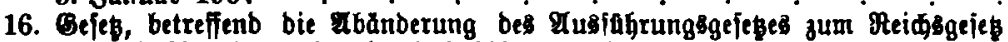

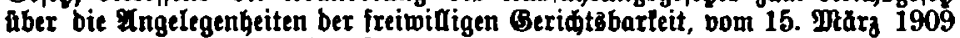

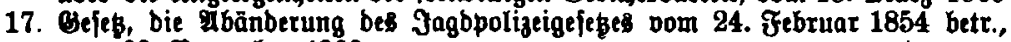
vom 29. November 1909

\section{XIX. dexjogtum Eadietroburgobotha.}

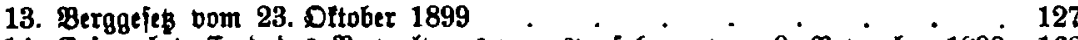

14. Bejeß, betreffend bas Berwaltungsgmangberfahren, vom 9. Robember $1899^{\circ} 168$

15. Gejes, betreffend bas Staatojuulbbud, vom 30. Eeptember 1903 . - 176

16. Befeß, betr. Die Bergtinftigungen und Bereøtigungen an ben Maldungen

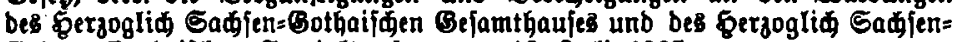
(Eoburg=(Gothaifiden Epezialbaules, vom 19. Juli 1905

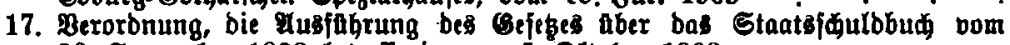
30. September 1903 betreffend, vom 5. Oltober 1903

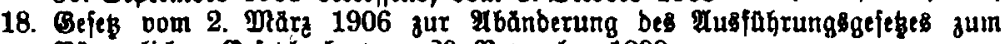
Burgerliden Belesbucise vom 20. Nowember 1899

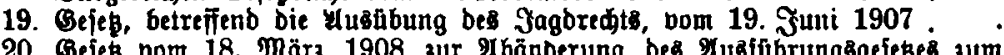
Burgerliden Oejebbude vom 20. Nobember 1899

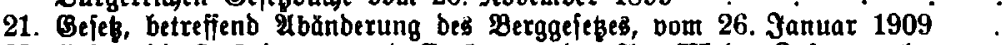

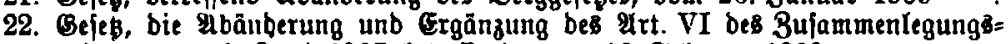
gejęe bom 1. Juni 1907 betreffend, oom 16. Żebruar 1909

\section{Sergogtum Eadienduetningen.}

15. Berggefeł bom 17. Ipril 1868 in ber faffung vom 18. Februar 1904 .

16. Berorbnung vom 9 . Juli 1904, betreffenb bie Rraftlozertlărung von Gdulb: bahtern (Einlagebthern, Sparbiduern)

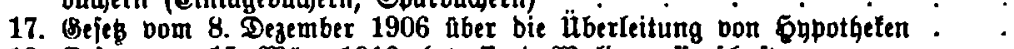

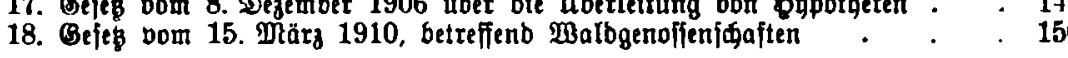

\section{Crobbersogtum Gabfendsetmar. Ctfenad.}

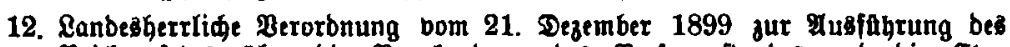

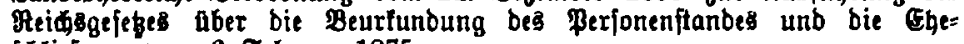

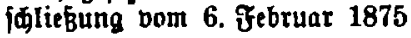




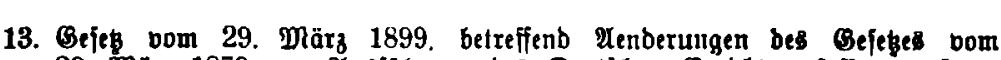

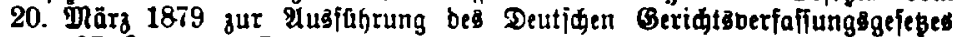
bom 27. Januar 1877

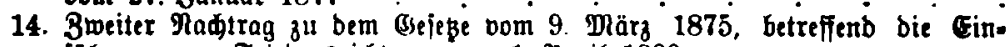
fürung bon Friebensiridtern, vom 1. थpril 1899

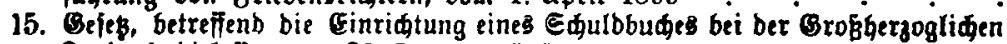
Rambestrebittaffe, vom 20. 3anuar 1900

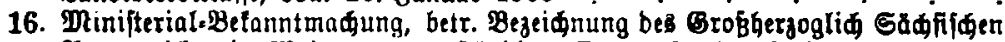

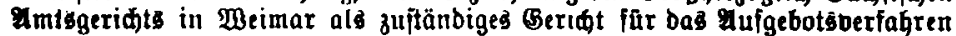

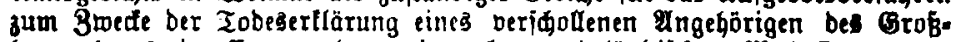

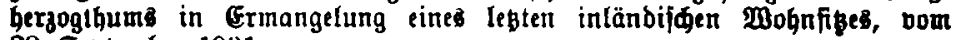
28. Eeptember 1901

17. Bejeß, betreffend bie Bejeitigung tes Borbefalts befierer $\mathfrak{H e d g t e}$ Dritter an Grunbitaden, vom 12. Dlärz 1902

18. Bejeb äber bie Grhaltuta ber zur Speijung on mafiferleitungen bienenben

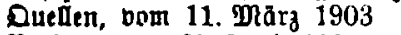

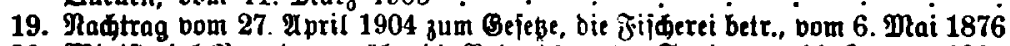

20. Phinifterial=23eroronung über bie Behanblung Der Funbe vom 11. Yanuar 1900

21. Bergzefę bom 1. $\mathfrak{T}$ ån 1905

22. Gejes nom 20. Dezember 1905, betrefiend bie vibänberung Des Berggefełes boun 1. Märs 1905

23. Dhinifterialberorbnung haber bie Fortiahrung Der Berg- unb Berghypotheten: buther, bom 21. Dezember 1905

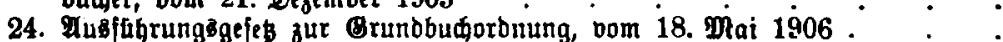

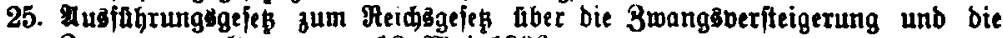
3wangsberwaltung, bom 18. Ytai 1906

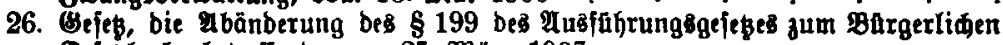
Gefezbude betreffend, bom 27 . Dă̆r 1907

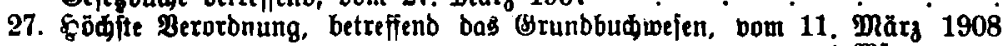

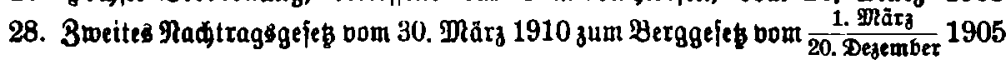

Geite

161

162

\section{8üftentum Sdyamburgsippe.}

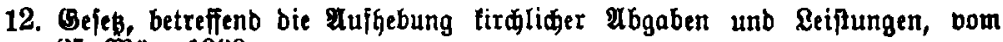
25. Piăr 1900

13. Befes, betreffend bie umigreibung voil auf ben Inbaber lautenben S̈buIb: beridreibungen auf ben Mamen Der Inbaber, vom 25. Plär 1900

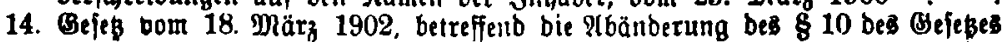
bom 19. Euguft 1899, betreffend bie Uüsfithrung ber Brunbbudorbnung far

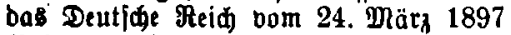

15. Befanntmađ̆ung, betreffent \&ugführunggbejtimningen zu ben 88980,981

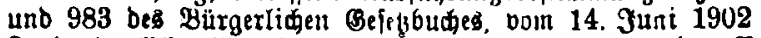

16. Ranbesherrlide Verorbulung, betreffetto abänberung ber Berorbnung vom

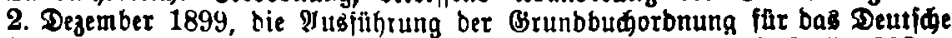

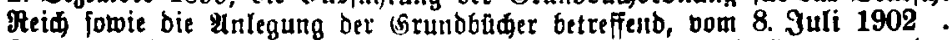

17. Ranbeşherrlide Verorbnung vom 17. Märg 1906, betreffend Crgănjung ber 3ur IuBfahrung ber Peidggruntobudoronung unb far bie Anlegung ber Grunbbaider erlafienen landesherrliden Derorbnung nom 2. Dezember 1899

18. Berggefés, vom 28. Mär 1906

19. Bejeg, betreffent Die Bejtrufung ber Dereitelung ber B̈wanggerziehung, vom 27. März 1907

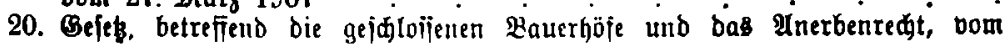
24. Prar 1909

\section{Güritentum Eqwarjburg:\$udoliftadt.}

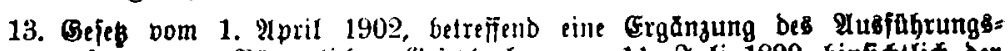

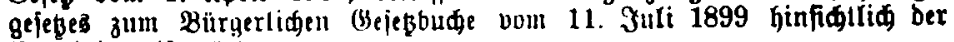
Gemeinberwaipenräthe 


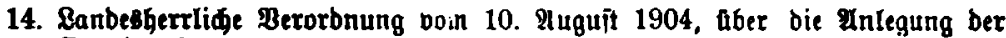
Brunbbäder

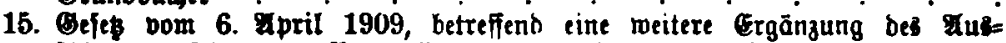

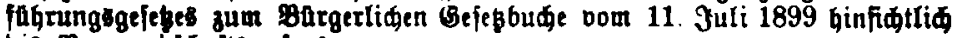
DiB Bormunbjuaftumefens

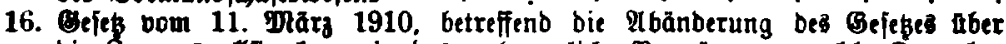
bie 3 trangsbouftreçung in bas unbemeglide Vermögen nom 11. Degember 1899, Ginfiditlid Der Cintragung von \$ypotheten

Seite

130

137

138

\section{Barfleutum Gowargburg-Oonbershanfen.}

14. Minifterialberoronung aber bie Bemeinberoaijentäthe bom 7. Ottober 1899

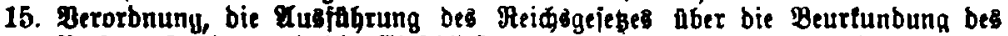
Ferfonenftandes unt bie Chejfließsung betreffent, oom 10. Dttober 1899

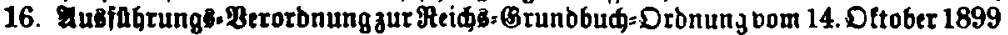

17. Minifterial-Derorbuung, betreffend Die Behanblung Der Fundjaden burt bie

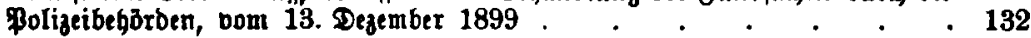

\section{Gäfientum salded.}

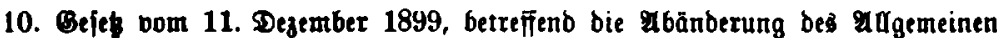
Berggejeses vom 1. Yanuar 1869

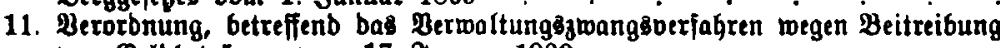
bon Belbbetrăgen, vom 17. Januar 1900

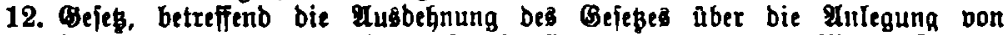

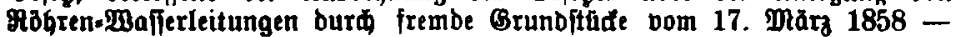
Megierunggblatt Seite 16 - auf Ranalifationten, bom 7. Januar 1901.

13. Seję aber bie fatjorgeergiehung Minderjähriger vom 22. Januar 1902 .

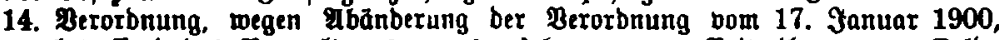
betreffend bas Permaltungszmangsberfahren wegen Beitreibung bort Belb= betrågen, bou 8. Fugult 1904 .

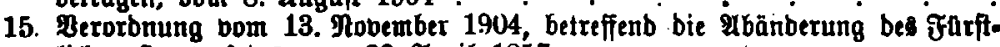

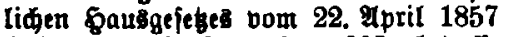

16. Befeß vom 6 . Dezember 1905 , betreffend bie anbermette 2 bånberung bes Gejepes aber bie Ginfahrung bes Preubijhen 2algemeinen Berggejęes vom

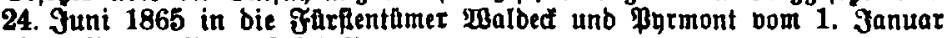
1869 (Plegier.=Slatt Sette 3)

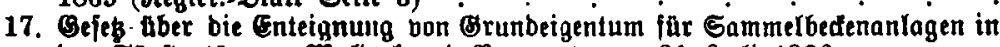
ben Farftentâmern 2 albed und Pyrmont vom 31. Yult 1906 .

18. BejeB, betreffend bie Finfahrung bes Notariats in ben Flarftentamern walbed unb Pyrmont, vom 4. Yalluar 1909 .

19. Bejeß aber bie Enteignung bon Erunbeigentum für mafferleitungen, $\mathfrak{A b}$ : wafferbefeitigungen jomic BaQ unb elettrijde Reitumgen vom 15. November 1909

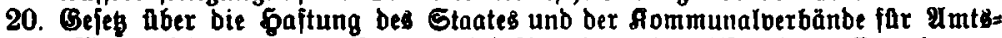

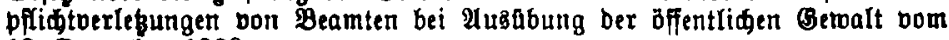
18. Dezember 1909

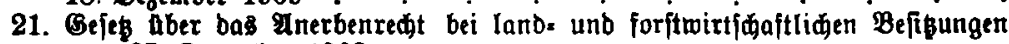
vom 27. Dezember 1909

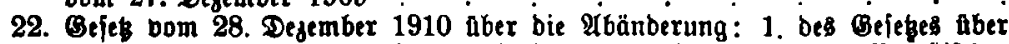

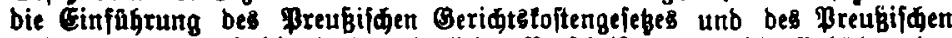

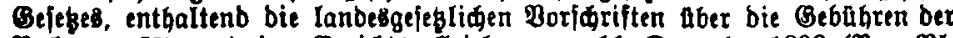

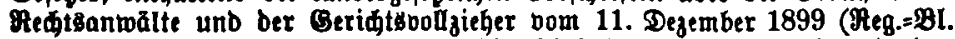
5. 186), 2. bes Gefetes betrefiend bie Cinführumg bes Rotariat in ben

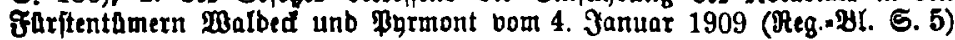

\section{ABnigreth garttemberg.}

3u Mr. 3. Beriळtigung

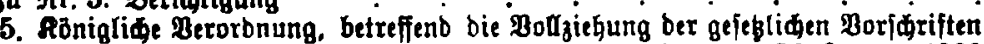

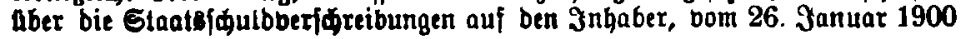


Gette

6. Waffergefes, vom 1. Dezember 1900 . 114

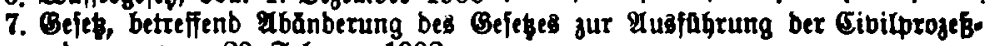
orbnung, Dom 20. Februar 1902 . 167

8. Cefeł, betreffend bie \$aftung für Sadjळaben bei bem Cijenbahnbetrieb, vom 4. Juni 1903 . 168

9. Dejet, betreffenb ben Leibgebingsoertrag, vom 2. Degember $1904 ; 169$

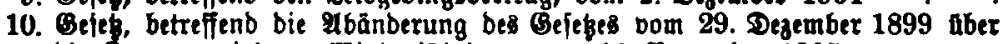

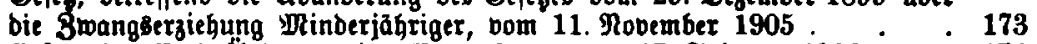

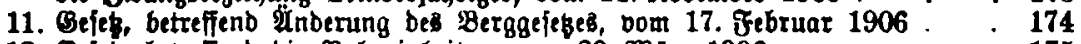

12. Beję, betreffend bie Bahneinheiten, vou 23. Maăr 1906.. . . 175

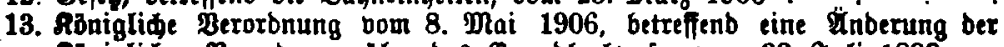

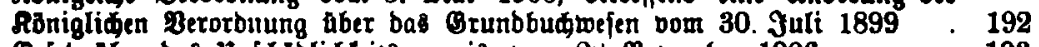

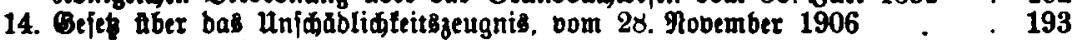

15. Befes, betreffenb bie Bertretung ber Drtsborfteger unb gatsidreiber in Den

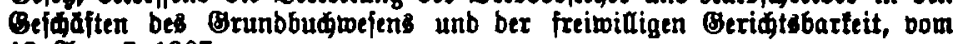
13. Eugufi 1907

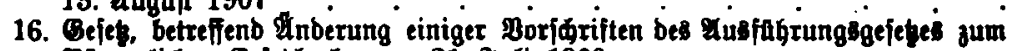

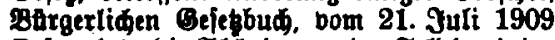

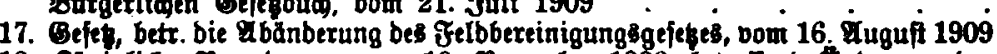

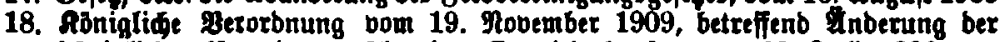
Reonigliden Berorbnung aber bas Grunbbudwefen bom 30. Juli 1899

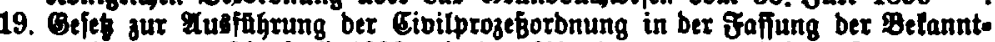
madung vom 31. Juli 1899 mit ben झbănberungen nad bem Gefepe bom 5. Jufi 1910

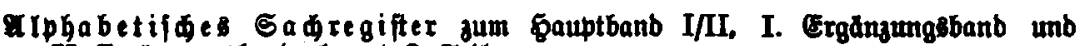
II. Exgànungşband, 1. und 2. Teil. 



\section{XIV \\ Rönigreich) Preussen.}

\section{Inhalts-Derzeidquis.}

15. Befek, betreffenb bas anerbentedt bei Mentens unb anfiebelunglgatern vom

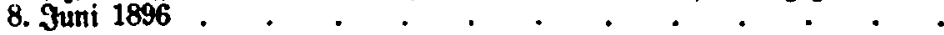

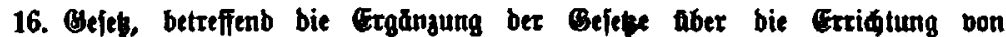
Mrarffeinen bom 7. Ottober 1865 unb bom 7. Etpril 1869, vom 24. Drai 1901

17. Jagborbmung far bie \$ohenzollemjónen sanbe vom 10, Marz 1902 .

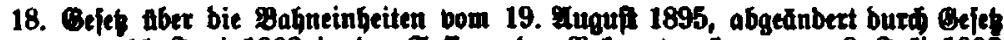
bou 11. Juni 1902 in ber Jaffung bet Betanntmadung bom 8 . Iuli 1902

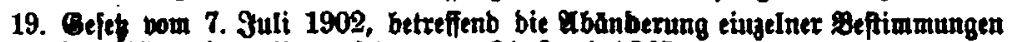
bes Allgemeinen Berggejetts vom 24. Jumi 1865

Eetite 209

20. Befes, betrefient bie tumlegung bon Branbftaden in Frantfurt a. $M$., bom 28. Э่̧uli 1902

21. Cefes wegen Eubbegnung bes Befetes, betreffenb bie ablofung ber Mtals Iaften in ber Probing Edsleswig.\$olfein, bom 3. Januar 1873 (Befef. GammL (5. 3) auf ben Areis Serzogtum Sautenburg, vom 29. That 1903

22. Befes, betreffend Befauung unb Benułung eqemaliger Mallgrumbftude in Granffurt a. 9 ., vom 4. Juni 1903 .

23. Berorbnutug wegen abănberung ber Peroronumg nom 15. Flobember 1899, betreffeub bas शistwaltungshmangtberfahren toegen Beitreibung von Oelb. belragen, vom 18. mår 1904 . . . . . . . . . 249

24. Befes, betr. bie Medfelproteftitumben, vom 1. Juni 1904 . . . . 250

25. Bejet, betreffenb bit Mubbehnung tiniger Beftimmungen bes Fugemeinen Berggetefes bour 24. Juni 1865 auf bie e्duffudung unb Betwinnung bon Crbõi, vou 6. Juni 1904 . . . . . . . . .

26. Befegh, betreffend bie Ausbegnung einiger Beftimmungen be gugemeinen Berggeferes vom 24. 3uni 1865 auf bie Frbeiten zur Fuffuhung von

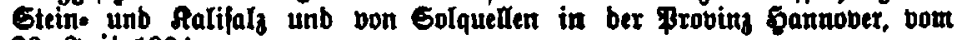
26. Эunit 1904

27. Befes, betreffend fahren unb bie Beridtigung bes Brumbbudea wodgrenb besfelben im stes gierungbegirle Miesbaben, bom 4. Tugujt 1904

28. Beleb ther bie Beffellung von Salgabbaugeredtigteiten in ber Proving

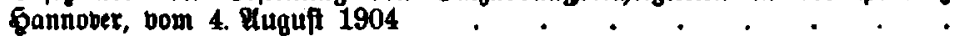

29. Befek, betreffend bie Brtinbung neuer Anfiebelungen in ben Provingen

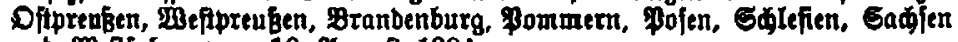
und Meffalen, bom 10. Yuguft 1904

30. Befes oom 5. 3uli 1905, betreffenb bie abanberung bes augemeinen Bexg= gejefel vom 24. Juni $1865 / 1892$

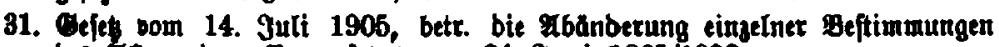

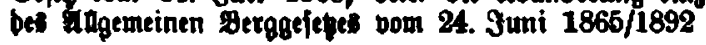




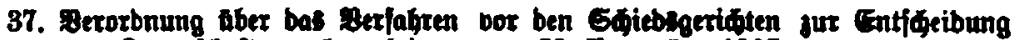
bon Anappidaftiangelegenbetten, boul 29. Flovember 1907

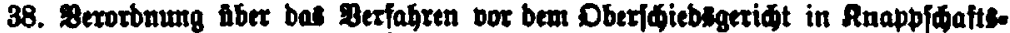
angetegenteiten, boun $\mathbf{3 0}$. Fovember 1907 .

39. Detorbnung ther bie Cinfuhrung bes Cefetes, betrefient bie Bulafiung

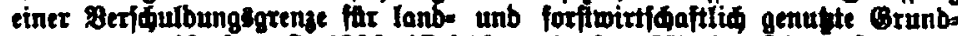
fille, bom 20. Uuguft 1906 (Cefetfamml. 5 . 389) in Difpreuben unb einem Xeile von 20 efipreupen, vom 23. Itär 1908. . . . .

40. Duellenjwubgejet, vom 14. Mai 1908 . . . . . . . . . 360

41. Beies, betreffenb bie Roppelfijuerei im Regierunglbegirle Cafiel, bom 19. Thai 1908 . . . . . . . . . . . .

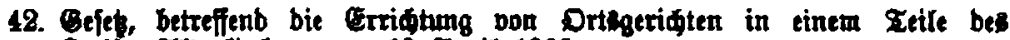
Rreifes alltentioben, bom 13. april 1909 .

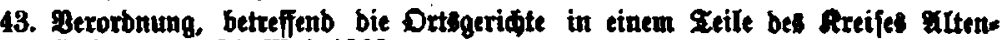
tithen, bom 24. Dtai 1909

44. Betorbnung aber bie Cinfubrung be Bejeges, betreffenb bie 3ulafiung

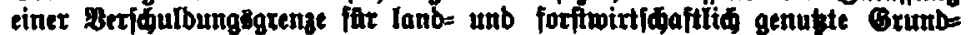
finte, vom 20. Suguft 1906 (Bejebjauml. E. B89) in Detien ber Probing Defipreuben und in ber proving \$ojen, bout 16. Juni 1909

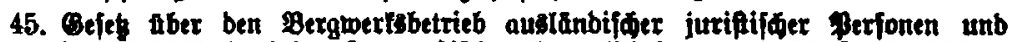

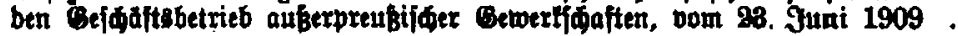

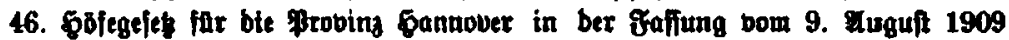

47. Beles, betr. ble Mbanberung bes allgemeinen Berggeleft vom 24. Juni 1865 $\frac{1805}{1892}$ und 14. Juli 1905, bom 28. Juli 1909 . • . . . . •

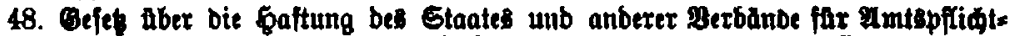
berlefungen bon Beamten bei Aubabung ber bffentliden Cetwalt, bom 1. Æugufit 1909

49. Derorbnung zur Fusfabrung Des Bejetes aber ben Bergwertsbetrieb aus-

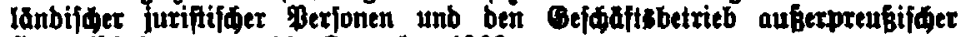
Bewerfigaften, bom 11. Dezember 1909 . . . . . .

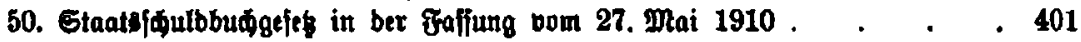

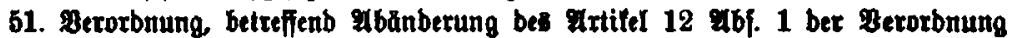
zur Iusfahrung bes Bargerliden Befetbuds nom 16. November 1899 (Belebjammi. 5. 568), vom 12. Juli 1910 . . . . . .



53. Berorbnung megen Jagbbarteit ber Brongeputer ober wilben Zrutbabner (Erutmilb), vom 9. Yuguft 1910

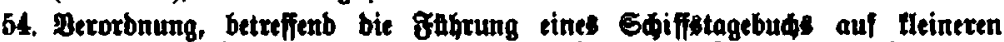
Fahrgeugen (Raftenfahrett unb bergleiden), bou 9. Degember 1910 . . 